\section{Griginal Commanications.}

\author{
ON THE NATURE, CAUSE, AND TREAT- \\ MENT OF 'TUBERCULOSIS.
}

By Horace Dobelc, M.D., Physician to the Royal Infirmary for Diseases of the Chest, etc.

\section{[Concluded from page 66.]}

Is the next place, I must point out that the order in which primary tuberculisation usually takes place in the principal organs, is consistent with my hypothesis and is explained by it.

The order is as follows. In edults and children, the lungs are by far the most frequent seat of tubercle. In adults, the small intestines and mesenteric glands are the most fiequent seat of tubercle except the lungs. In children, the bronchial glands are affected with tubercle more frequently than any other part except the lungs, and they may be tuberculous without the lungs being so. After the bron. chial glands, the small intestinos and mesenteric glands are the most frequent seat, as in adults.

The lungs are the organs, in adult life, in which, par excellence, the required combination of conditions for precedence in tuberculisation exists. The small intestine and mesenteric system are the parts most nearly resembling the lungs in this respect.

It is hardly necessary to point out that there is no other part of the body traversed by fluids essentially the same as thoso which traverse the lacteals, mesenteric glands, thoracic duct, and pulmonary artery; and that there are no other parts of the body at which the relations between fats acted upon by the pancreas, albuminoid tissue, and oxygen, are so similar as in the small intestine and mesenteric system, and in the lungs.

In the lungs, the oxygen is in the air and in the nutrient capillaries; in the intestine and mesenteric system, it is in the blood of the capillaries.

The explanation of the phenomenon, that the lungs occasionally gire place to the bronchial glands and to the small intestine and mesenteric system in the precedence of tuberculisation, and that this occurs especially in children, is not easy. But the difficulty is partly due to a want of precise knowledge of the facts of the case. For example :

1. It is not certain, in the case of glands, that the tubercle is formed in them, not carried to them.

2 . It is not certain how the interchange of oxygen from the air in the air-cells, with the carbonic acid in the blood of the pulmonary artery, takes place.

3. It is not certain to what extent the lung-tissue is nourished by the blood in the pulmonary cnpillaries.

4. It is not certain how the changes which take place in the fat that has been acted upon by the pancreas are effected during its course from the intestine to the pulmonary capillaries.

5. It is not certain what is the limit and essential condition of absorption of fat by the portal system.

So far, however, as these and other difficulties permit, my bypothesis offers a fair explanation of the phenomena of precedence in tuberculisation. The temporary protection to the lungs is afforded by fluid fats absorbed by the portal system, and thus carried to the lungs independent of the pancreas and mesenteric system. That the blood of the portal vessels is susceptible of such a function cannot, I think, be donbted, when we reflect that, in a normal state, the portal blood is twice as rich in fat as other venous blood; that, most probably, it is finid oleinous fat, which is especially susceptible of absorption by blood-ressels; that the diet of children is peculiarly rich in such fats; and that in milk and cream the fats are minutely divided, and so arranged that in gastric digestion they must be mixed intimately with other foods, and thus be placed in the most favourable position for absorption; and when we also remember the readiness with which correlated organs assume compensatory functions.

It is, then, probable that, under certain circum. stances, and especially in children, the oleine carried to the pulmonary circulation by the portal system may protect the lungs for a sufficient time to give other organs not 80 protected tho precedence in the order of tuberculisation.

It is easier to sec why, by these means, the precedence should fall upon the small intestine and mesenteric system, than why it should fall upon the bronchial glands. But it is possible that the protection given to the lungs may, in some cases, be suffcient to prevent disintegration of the albuminoid tissue during the direct combustive process, and thus to prevent a primary deposit at the point of origin; but not sufficient to prevent tuberculisation during the interstitial nutrition of the lungs; and thus the bronchial glands may suffer either because of the activity of their life in childhood, or because the disintegrated albuminoid matter is carried to them by the lymphatics as it is disengaged in the neighbouring tissues, constituting a primary deposit distant from the point of origin.

Supposing this explanation to stand, it involves also an explanation of the curious and inconstant relationship between fatty liver and phthisis; for which I have not been able to find any other that is more satisfactory.

In the years 1851-i853, I very closely and carefully investigated the question of fatty liver in phthisis examining and analysing a large number of cases and pathological reports, at St. Bartholomew's Hospital and elsewhere, in the hope of finding some explanation in the clinical histories of the cases. On referring to my notes of that date, I find the following summary. In cases of phthisis : 1. Fatty liver is not more frequent in those cases in which the normal strusture of the lungs is extensively destroyed than in those in which such destruction is slight. It is not, therefore, due to diminished pulmonary function. 2 . There is no constant relation between the condition of the appetite and the existence of fatty liver, nor between the degree of emaciation and fatty liver. 3. There is no constant relation between the state of the borvels or skin in fatty liver; they may both or one act in excess or not in excess and fatty liver exist or not exist. (Diarrhœa is, however, more frequent in phthisis with fatty liver than without it.) These conditions may, one or all, be combined with great destruction of lung-substance and great emaciation and fatty liver exist or not exist. 4. The intimate relation between the portal and hepatic capillaries may allow the liver to become the seat of deposits from the elements of portal blood. 5. Supposing the portal system, in some cases of phthisis, to take on a compensatory furction, and to absorb an inordinate quantity of oil from the food, this might be deposited in the liver even though the rest of the body were emaciated.

To this summary, I may now add, that Dr. Ormerod's recent experiments on fatty degeneration (Review of the Present State of Cardiac Pathology. By E. L. Ormerod. 18(64) showed that the fat of degeneration is oleine, not margarino; and this renders more probable the explanation I have offered of the occasional occurrence of fatty liver in phthisis from 
the undue absorption of fluid fats by the portal system.

It is wo obvious that all the phenomgna in the following group are at once explained by my hypothesis that I need not do more than place them in juxtapogition.

a. The rapid and marked improvement, which takes place in many cases of phthisis when substances rich in oleine are first supplied by the stomach.

$b$. The want of permanence in this effect (except under peculiar combinations of circumstances, which include the causes of restoration of pancreatic function.)

c. The beneficial effect of a renewed exhibition of oleine after it has been for some time withdrawn, although it had ceased to benefit while previously continued.

$d$. The repetition of these phenomena, with less and less marked benefit, and coetaneously with a steady decline of the patient.

e. In a large number of cases, ultimate intolerance of the oleine, which previously had been much desired.

The next group of phenomena explained by my hypothesis is rery curious. While engaged, during the year 1853, in the investigation of fatty liver in phthisis, to which I have referred, I was struck with the fact that the following group of phenomena may be found at the same time in a case of tuberculosis, and I attempted to discover a satisfactory way of explaining their apparent incongruities.

a. A considerable proportion of the lungs deprived of decarbonising and oxidising function.

b. A fair appetite and the ingestion of a normal quantity of food.

c. A difficulty in maintaining equalised animal heat thronghout the body.

$d$. A steadily progressing loss of carbon from the tissues.

e. Blood not surcharged with carbon.

$f$. No sickness, diarrhoea, or other flux.

g. Arrested menstruation in females.

The most satisfactory explanation appeared to be an assumption that the fat-elements of the food did not find their way into the blood of the right heart in normal proportions and conditions. With the hope of finding support for such an explanation in a coincidence of disease of the pancreas and tubercalosis, I searched and analysed the pathological reports at St. Bartholomew's and elsewhere, in which the condition of all the organs was to be found noted. But in every case of uncomplicated phthisis in which the pancreas was mentioned, it was reported "healthy".

In consequence of this disappointing result, I set down as subjects for future work, the questions :

1. What evidence can be found that the pancreatic secretion can be deprived of its normal properties without leaving traces of structural disease in the pancreas?

2. Are there not affections of the pancreas competent to deprave its secretion, but which have not hitherto been recognised as disease?

Both of these questions may now be answered in the affirmative, almost with certainty.

In answer to the first, I must refer to the careful and often repeated experiments of Professor Bernard. They show that when the nerves of the pancreas are acted upon, either by excitation of the cerebro-spinal or by section of the sympathetic fibres, the secretion grows abundant and uninterrupted, while a profuse diarrhcoa is constantly established. Extirpation of the semilunar ganglion produces similar effects; and under these special conditions the pancreas pours forth a peculiar fluid which no longer exhibits the physiological properties of the secretion. When the secretion is thus rendered continuous, the character. istic active principles are no longor produced within the gland, and the watery vehicle alone escapes from the secreting apparatus. Bernard particularly insists upon the important fact that "the general perturbations of the economy" exert a powerful influence upon the functions of the pancreas, and the least degree of inflammation in its neighbourhood perverts the properties of the pancreatic juice. (Bernard's Lectures on Physiology, Medical Times and Gazette, 1860.)

I have been informed by a butcher who deals largely in calves' sweetbreads, and is a shrewd and observant man, that there is a great difference in the qualities of sweetbreads, dependent upon the pre. vious state of the nervous system of the animal. If the calf have been brought to London comfortably in a cart, the sweetbread is generally in good condition; but, if it have been "worried about", he is often obliged to throw the sweetbread away, as not good enough for sale.

From the effect of nervous influences upon secre. tion generally, especially upon that of the salivary glands, the stomach, and the mammary gland (see Carpenter, 6th Edition, pp. 738 to 744), we might reasonably expect by analogy that the pancreas would suffer in the manner shown by Bernard.

It is evident, then, that the pancreatic secretion can be deprived of its normal properties by causes acting through the nervous system, both cerebro. spinal and sympathetic; and by affections of noigh. bouring organs. Such causes may be of a temporary or of a more permanent nature, and, unless of long duration, may not leave traces of structural disease in the pancreas.

I particularly desired that, before publishing my hypothesis, I might be able to bring forward abso. lute proofs of the nature and extent of the perverted or arrested function of the pancreas in tuberculosis, in the form of results of direct experiments upon the pancreatic juice of persons dying of phthisis. Through the kindness of Drs. Quain and Symes Thompson at Brompton Hospital, of Dr. Cayley at the Middlesex, and of Dr. Andrew at St. Bartholomew's, together with my own opportunities at the Royal In. firmary, I was able to obtain a supply of specimens; and, with the invaluable chemical assistance of $\mathbf{M r}$. Heathorn, I commenced a systematic examination of the properties of the pancreatic secretion in phthisis. 'These exceedingly troublesome experiments were carried on with great care from the beginning of November 1864 till the beginning of March 1855, and a detailed report kept of the results; but I regret to say that they were obliged to be finally abandoned. from a conviction that we were wasting our time. The results wore utterly valueless, for the following reasons.

1. We had no standard of healthy pancreatic secretion for comparison.

2. Our attempts to form such a standard were fiustrated by the impossibility of getting the human pancreas under circumstances which did not vary considerably in the following essential conditions:

a. Number of hours between death and the last meal.

b. Character of the last meal.

c. Cause and mode of death, and nature of co. existent diseases.

d. Number of hours between death and the post mortem examination.

e. Number of hours between death and commence. ment of experiments on the secretion.

These obstacles to the establishment of a healthy standard all equally existed in the case of diseased 
specimens. In addition, it was proved by experiments upon the lower animals, that no reliance can be placed upon the characters of the pancreatic secretion when not examined till twelve hours after death; whereas the average number of hours between death and post mortem examination for all of our cases was 27.5 hours, the minimum being 9, the maximum 54. I give these details of failure, in the hope that some one working within the walls of a hospital may find it practicable to get over these difficulties, and to prosecute this important inquiry under conditions which justify confdence in the results. To any one undertaking such experiments, I shall gladly give any assistance in my power. I can at least point out some sources of fallacy to be avoided, and some of the means of success.

In answer to the second question-" Are there not affections of the pancreas competent to deprave its secretion, which have not hitherto been rocognised as disease?"-I am permitted by Dr. Fenwick to state in general terms, that the results of a large number of examinations made by him of the pancreas in man and the lower animals show a peculiar liability of this organ to different forms of degeneration. But, as it is probable that Dr. Fenwick will himself make public his observations, I forbear from giving them in more detail.

The fact, then, which in 1853 appeared to show that defective pancreatic action could not be essentially connected with tuberculosis-viz., that, in all the cases of uncomplicated phthisis that I could discover in which the pancreas had been examined, it was reported healthy-need no longer be considered of any value as an argument against my hypothesis; whereas, on the other hand, the observations of Professor Bernard must be considered as important evidence of its truth.

But the most remarkable evidence of the truth of my hypothesis is this, that it explains in the simplest manner a mass of apparently incongruous facts in the etiology of tuberculosis, which no explanation hitherto attempted has been at all competent to deal with in a group. I refer to such established and recognised causes of phthisis as are agreed upon by the general verdict of physicians and the public. I will abstain from adding any that I might myself be disposed to suggest, and select from reliable authors those which are apparently least in accord with each other.

The question is, How can a constant result-viz., the formation of nascent tubercle-be produced by the following causes?

1. Disappointment; home-sickness ; longings after the objects of affection, either absent or lost; and other depressing influences.

2. Whatever depresses vital power-exhausting passions, poverty, and the vicissitudes of life.

3. Persistent defective expansion of the chest, and defective exercise of the respiratory powers.

4. Persistence of young persons in a diet deficient in milk.

5. Inattention to a due preservation of the cutaneous function.

6. Chronic alcoholism.

7. Neglect of exercise in the open air; deprivation of sunlight; congregation of numbers in a close or insufficiently ventilated place. "If disease of a given form be so associated with certain conditions that, in two-thirds of the instances which present themselves to our notice, these conditions be present, we cannot avoid referring the diseased result to the antecedent error. In other words, deficient ventilation and crowded apartments are eminently productive of tubercular disease......The effects of posture are chiefly observable in bootmakers, tailors, hand-weavers, and others whose work necessitates the stooping posture. The results are mechanical hindrance to the free entrance of air to the chest, restricted expansion of the bony wall, and an imperfect respiration. In the case of bootmakers, there is the addition of pressure on the epigastrium, which gives rise to the well known neurosis. But, on the whole, all the errors of this class are to be referred to insufficient expansion of the chest." (Pollock, Elements of Prognosis in Consumption, p. 368.)

8. "Rebreathed air."

9. Cyanosis.

10. Diabetes.

11. Acute diseases, especially continued fever.

12. Childbirth.

13. Superlactation in mothers.

14. Weaning in children.

15. Hereditary taint.

These causes of phthisis may be assembled under four heads.

1. Causes which act directly upon the pancreas, either specially, or in common with other internal organs; e. g., hereditary tendency to disease of the pancreas; occupations causing pressure upon the abdomen in the pancreatic region; acute diseases, especially continued fevers; inflammatory affections of neighbouring parts.

2. Causes which act indirectly upon the pancreas, by diminishing the elimination of carbon from the blood, and thereby reducing the normal call for the introduction of fat from the food into the blood. By these means, the pancreas is kept in a state of inactivity and low nutrition, until in time its secreting powers are depraved or destroyed, and the organ itself becomes degenerated, in accordance with the laws goveruing all other secreting organs.

It is evident that this heading will include a large number of the causes of phthisis which I have enumerated; e.g., all those which diminish respiratory blood-changes for protracted periods, whether it be simply through deticient expansion of the chest, or through the hypercarbonetted condition of the air presented for respiration ; and all causes of deficient excretion by the skin, especially if combined with defective respiratory action. It will also include cyanosis and chronic alcoholism.

Cyanosis is a condition which would, at first thought, appear to be antagonistic to my hypothesis; for, if tubercle is produced by the combustion of the fat-elements of the albuminoid tissues, it would seem that a disease in which the blood is persistently surcharged with carbon would, par excellence, be protective against tuberculosis. But the contrary is the fact; and it is easily explained. It is only protracted cyanosis that ends in tuberculosis. In these cases, the long continuance of hypercarbonetted blood paralyses the function of the pancreas. But, as it is not carbon only that is requisite to maintain nutrition and protect against tuberculosis, but fat properly prepared by the pancreas, after a time the albuminoid tissues are invaded to supply the fat-elements which the pancreas has lost the power to prepare, and tuberculisation results.

In chronic alcoholism, the mode of operation is somewhat similar to that in cyanosis. A form of hydrocarbon is thrown into the circulation through the portal system, which substitutes the normal supply of fats by the lacteal system. The affinity of oxygen for alcohol being greater than its affinity for fat, respiration is supplied from this artificial source with carbon for direct combustion;, an artificial nutrition is kept up, in which the natural call for fat is stopped, and the function of the pancreas is reduced to supplying the minimum quantity necessary for 
histogenetic purposes. To this inactivity of the organ is added the usual tendency to degeneration due to alcoholism. In course of time, the pancreas loses that minimum amount of function which it had been allowed to exert, and fails to supply even so much fat as was necessary to protect the albuminoid tissues, and tuberculosis results. Or, as frequently happens, the toper ceases to obtain his supply of alcohol, either from inability to get it, or from inability to absorb it or to retain it on the stomach. His artificial supply of carbon, upon which he has been depending, is thus cut off; a sudden call is made upon the pancreas for that which it has now lost the power to give; the tissues are disintegrated to supply the required fat-elements ; and tubercle is produced.

3. Under a third head may be included causes which deprive the system of carbon to such an undue extent that the pancreas cannot keep pace with the demand made upon its function; the supply of fat to the blood becomes insufficient to keep up the waste ; and the albuminoid tissues are invaded. This may be the case when those who inherit a tendency to disease of the pancreas, or who have acquired a feeble secreting power in the organ, are exposed to drains upon their fat-elements which in healthy persons might be met by increased function. It is thus that, in tuberculous families, childbirth and superlactation, especially when not protected by proper diet and regimen, precipitate the patient into tuberculosis ; and, as the mother is deprived of fat-elements by lactation, so is the child deprived of them by persistence in a diet deficient in milk. In the case of the child thus deprived of fat, a double injury is done-first, by cutting off the supply of fat-elements necessary for the protection of the tissues; and secondly, by paralysing the function of the pancreas by prolonged inactivity.

Under this heading also must be placed diabetes. Tuberculosis occurs in diabetes when the excessive drain upon the carbon by the excretion of the carbohydrates, as sugar, is not duly supplemented by a corresponding supply of fat in the food, or when the demand for pancreatic action has become so excessive that the pancreas is no longer able to keep up to it. Then the albuminoid tissues are attacked, and tuberculisation occurs.

4. A fourth head will include all causes which act powerfully in depressing the nervous system, either suddenly or gradually, and by this means pervert or paralyse the secreting function of the pancreas. It is in this way that "the vicissitudes of life" bring on tuberculosis, especially in those who by hereditary transmission have a tendency to depraved pancreatic function, or in whom the causes of nervous depression are conjoined with some of the other causes of disease of the pancreas which have been enumerated. Under this fourth heading, therefore, we must place all forms of shock to the cerebrospinal or ganglionic nervous systems, and all such causes of mental and nervous depression as disappointed love or ambition, excessive grief, unrequited longings, hope deferred, and the like.

Having given a fair example of the way in which my hypothesis coordinates and explains apparently incongruous and irreconcilable phenomena connected with tuberculosis, let me point out that it also affords a satisfactory explanation of the variable course of tuberculosis in different cases.

1. A sudden, almost complete, or total suspension of normal pancreatic secretion, accounts for acute tuberculosis.

2. A less complete suspension or perversion of the function of the pancreas accounts for chronic tuberculosis.

3. Either of the above changes of pancreatic se- cretion, occurring intermittently, accounts for recurrent tuberculosis.

I have next to speak of that portion of the hyp? thesis which assumes a change in the absorbing power of the small intestine, by which the passag of fats into the blood may be prevented after the function of the pancreas has been restored.

That the continual passage, through the delicas absorbent apparatus of the intestinal mucous meno. brane, of a depraved pancreatic secretion, and $8 \mathrm{f}$ food that has not undergone those changes which it to be brought into contact with the absorbing sur. face, must damage the apparatus, is a conclusion which analogy justifies us in assuming to be correct That such damage does occur in the alimentary canal of the tuberculous, is amply proved by a path logical research; and the extreme difficulty of iden. tifying, after death, delicate changes in the condi tion of mucous membranes, renders it certain tha such changes may continually occur without being recognised in a post mortem examination.

Bernard found that, in dogs who had been de? prived of their pancreas, the fæces commonly becan streaked with blood, as from ulceration of the intes. tines. (Mémoire sur le Pancreas, 1850.)

Bidder and Schmidt observed, in their experg ments on the lower animals, that inflammation of the mucous membrane of the intestine at once pre vented the absorption of fatty chyle by the lactealso

To say the least, it is in the highest degree pro bable that perverted pancreatic secretion, and foot improperly prepared for absorption, passing over the mucous membrane of the intestine from day to day, do, sooner or later, so damage its absorbing function as to add an additional obstruction to nutrition $h$ the lacteal system; and, as Bernard has shown tha the general perturbations of the economy, and the slightest inflammation in the neighbourhood of the pancreas, especially in the intestine, pervert the pro perties of the pancreatic juice, any damage done to the mucous membrane of the neighbouring intestin by imperfect pancreatic action must react upon it cause, and throw a double difficulty in the way of restoring either the pancreas or the mucous menf brane to a healthy condition.*

Treatment.
Assuming my hypothesis to be correct in its chief parts, the following are the principles of treatment which it indicates.

1. If the case be so far advanced that it is consio dered hopeless to aim at restoring the function of the pancreas and the absorbing power of the intes? tine, two principles must guide our treatment.

A. To supply the greatest amount of fat to the blood that is possible by other means than through the action of the pancreas.

a. By giving pancreatic emulsions of solid fat, on if these be rejected, pancreatic emulsions of oil, in the bope that some absorbing power for such mat? ters may yet remain in the digestive tract.

$b$. Chiefly, by giving olein, with a view to its $a b$ sorption by the portal system of vessels; and b广 rubbing it into the surface of the body and limbso with a view to its absorption by the skin.

c. By giving highly albuminous food in conditions़्?

* From my own observations, I am disposed to think that laryn-O geal phthisis will be found to occur more frequently in persong who have slept, night after night, with patients suffering from th last stage of consumption, than in other persons; and that mole cules of tubercle may, in this way, be occasionally transplanted by the breath from the lungs of one person to the respiratory pas sages of another, then being carried by the lymphatics into the circulation, producing tuberculamia and secondary deposits. circulation, producing tuberculmmia and secondary deposits.
am not prepared to say that this is the case: but to suggest am not prepared to say that this is the case: but to suggest
as an important subject for further clinical and pathologieal ob servation. 
in which it may be most easily utilised, so as to supply an excess of material as a source of carbon by disintegration.

$B$. To save the albuminoid tissues from disintegration to the greatest possible extent.

a. By supplying a surplus of carbohydrates, so as to economise as much as possible the consumption of hydrocarbons.

$b$. By diminishing the proportion of oxygen in the air presented to the lungs.

$c$. By diminishing the demand for the generation of animal heat, by supplying it artificially.

d. By reducing respiratory and cutaneous action to the lowest point consistent with maintaining what remains of appetite and digestive power.

It is obvious that the persistence in these means must be considered utterly at variance with curative intentions, and simply as the expedients best fitted to prolong the process of gradual death.

2 . If the symptoms be only what is commonly called "premonitory"-that is, if they be those of commencing tuberculosis, and no reason or sign be discoverable which justifies the suspicion that tuberculisation has commenced; if a sufficiency of fatelements remain, without calling upon the albuminoid tissues - the principles of treatment are quite opposite to those last detailed. They are now entirely curative in their intention.

$A$. To restore the function of the pancreas as quickly as possible, by placing the patient under those conditions which call for pancreatic action.

a. An atmosphere rich in oxygen.

b. A climate at once cold and dry.

c. Exercise of the respiratory and cutaneous functions.

$d$. Cheerfulness of the mind and quiet to the emotions ; exhilaration of the animal spirits.

e. A good mixed diet, easily digested, and free from substances irritating to the mucous tract.

$f$. Pancreatic emulsions of solid fat and pancreatic juice in quantities sufficient to ensure protection to the albuminoid tissues while the process of restoration is going on in the pancreas, but not in such quantity as to entirely supplant the natural pancreatic function and thus to counteract the measures adopted for calling it into action.

These two classes of cases represent the two extremes in the history of tuberculosis - the greatest and the least hope of cure.

3. A third class of cases, intermediate between these extreme points, represent the bulk of all those brought under the care of the physician. They require a combination of the two principles of treatment already stated. The nice adjustment of these two plans of treatment-the hopeful and the hopeless, the palliative and the curative-calls for all the intelligence and judgment that a medical man can possess.

If tuberculisation, even in the smallest degree, be going on, the first and most urgent need is to supply fats. Olein should be given for absorption by the portal system, and thus to afford, so far as it is able, materials for combustion. But, above all, fats acted upon by pancreatic juice are called for, and must be supplied until the deficiency is removed, the just balance restored, the process of tuberculisation stopped. Until this point is arrived at-until the balance is turned in favour of the albuminoid tissues-everything which favours the reception of oxygen into the blood, everything which increases the wear and tear of the body, everything which calls for the generation of animal heat, directly favours tuberculisation, and precipitates the patient into the very catastrophe we wish to avert.

On the other hand, so soon as the balance has been turned in farour of the albuminoid tissues, and tuberculisation has been artificially arrested, everything which postpones the restoration of the function of the pancreas directly favours the conversion of a temporary into a permanent disease. But moderation is essential to success. Too great and too sudden a demand upon a weak and defective pancreas may only paralyse the organism in its attempts at restoration of function. It is, however, impossible to magnify the importance of periods of arrested tuberculisation, whether artificially or natur'ally produced. They are the bright opportunities for the permanent restoration of pancreatic function. Too often these opportunities are wasted. The patient and his friends, pleased with the marked improvement that has taken place under some plan of treatment, either continue this treatment long after its proper time and place have passed by, or give up treatment altogether, content to wait till signs of active disease return. In either case, an opportunity for establishing a permanent recovery is thrown away, and perhaps it may never return.

It must not be forgotten that, when tuberculisation and tuberculosis have been stopped, when the function of the pancreas has been restored and the intestinal mucous membrane brought back to a normal condition, there may yet remain tuberculæmia. From time to time, fresh blood-poisoning may occur from the absorption of deposited tubercle; and, if there be any considerable quantity deposited, this chronic blood-poisoning may become a tedious and dangerous disease. The absorbed tubercle may be again deposited and again absorbed, and thus keep up a ceaseless repetition of morbid changes somewhat analogous to those witnessed in pyæmia. Treatment directed to the blood-poisoning will, therefore, be imperatively called for in most cases of tuberculosis which have advanced to the stage of tuberculisation.

I have long been aiming at testing my views regarding the action of the pancreas in tuberculosis by a crucial experiment; but the difficulties in the way of artificially supplying pancreatic juice to a number of patients were so numerous that they were not finally overcome till the summer of 1863 . With the valuable assistance of my friend $\mathrm{Mr}$. Heathorn, who had long been working with me at the subject, I succeeded in obtaining a pancreatic emulsion of fat sufficiently palatable and in sufficient quantity to permit of my beginning my crucial experiments by administering it to patients suffering from tuberculosis at the Royal Infirmary for Diseases of the Chest. For some time our supply was too fluctuating to allow of the experiments being carried out in a manner that $I$ thought justified me in making the results public; but in the summer of 1864 . I was able to draw up the first of the three reports which have since appeared in the Lancet. This was published September 10th, 1864; the emulsion used in the reported cases being made of beef-fat and the pancreatic juice of the pig. The next report was published June 10th, 1865; the emulsion used in those cases being made of lard-oil, and the pancreatic juice of the pig. The last report was published November 11 th and 18th, 1865 ; some of the cases having been treated with the lard-oil emulsion, and some with the emulsion of suet and pancreatic juice of the pig. The number of cases in the three reports is eighty-nine; but, out of these, only twenty were in the first stage, and in these the deposit of tubercle was considerable, and the general symptoms very marked; in fact, they were, as a rule, just passing into the second stage, before applying for treatment at the hospital. It is obvious, therefore, that, although the results were remarkably satisfactory, 
there was not in one of the cases the opportunity of trying the treatment in the most hopeful stage. In addition to this, I must remark, that for a long time, until I was satisfied of the good effects of the emulsion, I did not feel justified in giving it unless for some reason the patient refused to take cod-liver oil; so that this added another unfavourable feature to the cases selected for experiment. And, again, it is important to bear in mind that the emulsion, as we first prepared it, was necessarily in a much less satisfactory condition than the emulsions used in later experiments. From time to time, Mr. Heathorn introduced great improvements in the mode of manufacture, and these have been still further carried out by Mr. Schweitzer; so that the emulsions, as now sold by Messrs. Savory and Moore, are far more satisfactory in every respect than those which we employed for the hospital cases included in my reports.

Those accustomed to hospital practice will know well that the chances of treating tuberculosis in its simple and early stage, before the occurrence of tuberculisation, are very rare. Patients do not apply at hospitals for relief until they have some marked symptoms of disease, such as hæmoptysis or purulent expectoration. When by chance they are seen in an earlier stage, they discontinue treatment directly the first feeling of debility is allayed. It is in private practice that the opportunity arises for detecting commencing tuberculosis; and it is especially within the province of the family doctor, frequenting the houses of his patients for other maladies, to keep a watch, especially in consumptive families, for the earliest dawn of impending tuberculosis.

In conclusion, I wish particularly to impress that, if the views here brought forward are correct, the importance of pancreatic emulsions of solid fat over cod-liver oil, in the treatment of tuberculosis, must be as great as that of supplying a plant with good soil instead of putting it into water. In the one case, a provision is made for the maintenance of normal life; in the other, death is only postponed by a temporary expedient.

Harley Strcet, January $18 C 6$.

NOTES ON SOME OF THE CAUSES WHICH OCCASIONALLY 'TEND TO ENDANGER FOETAL LIFE DURING LABOUR:

WITH REMARKS ON SOME OF THE MEDICO-LEGAL BEARINGS.

By G. K. H. Paterson, L.R.C.P.Ed., L.R.C.S., Balbeggie, Perthshire.

[Read before the Perthshire Medical Association.

Is general domiciliary nidwifery, it will not, I trust, be disputed for a moment that occasionally is witnessed the occurrence of, or, if not, the tendency to, " hazardous states" in certain kinds of labour, calculated more or less to endanger fœtal life. Doubtless, not a few labour-cases-oftener in some years than in others-at the first visit by the summoned medical practitioner, are found in their early stage, and, to the best of his judgment, favourable; in which, however, it is far from being uncommon to find, when an eramination per vaginam is later made, that they have become either difficult or complicated labours.

Accordingly, it will be allowed, from the occasional uncertainty of the result in these cases, that it is an important and valuable attainment in midwifery practice to be able to make a right discrimination between the nature of the presentation in each individual case from others known to happen, as well as timely to determine as to the mode of management most fitting, and when to proceed in aiding the parturient woman; whether it be by administering needful nourishment or other means internally, or $\overrightarrow{\vec{F}}$ by the mouth, or by having timely recourse to arti- $\frac{\text { P }}{4}$ ficial interference with the same end in view, to promote and procure as speedy delivery as possible, with safety to the mother and to the child.

Having thus premised, I now proceed to state my $\frac{\sigma}{\overparen{D}}$ views in detail, though briefly, as follows.

How far the tendency oftentimes, in difficult and complicated labours, to endanger fotal life, may be obviated, must undoubtedly depend much on the na- $\overrightarrow{0}$ ture of the presentations and severity or tediousness of the cases, and on their management. Putting $\vec{\omega}$ off proper medical assistance too long, or not sending for it in time, often endangers the lite of the fœtus.

The management of cases of lingering or difficult 3 . labour (although often there is no occasion for over-anxiety from fear of danger), when timely and pro- iv perly attended to, often ends well for both lives.

Cases of difficult labour have hitherto come often under my observation with cephalic presentation $\vec{\omega}$ chiefly, not a few of which, as might be expected, were accompanied in primiparæ with rigidity of $\frac{\mathrm{O}}{\mathrm{a}}$ parts; and the labour in some of these went on with considerable difficulty, owing to the os uteri and $O$ other parts taking a much longer time than ordinary 7 to dilate and relax before the foetal head was suffi- $\frac{\mathbb{O}}{0}$ ciently advanced for delivery, notwithstanding the previous use of internal means. Where, on the other hand, there were present (rendering the labour, for the time they lasted, more than usually slow and $\vec{\infty}$ difficult) signs in the maternal passages of coiling of
the fœtal cord round the neck, and where, in such labour, ergot of rye had been early made use of, and $\square$ before the head was well advanced, I have seldom seen the expected benefits accruing from the ergot favourable to the fœetus.

In my own practice, coiling of the cord round the neck or body of the foetus has been found only in the $\frac{\mathrm{O}}{\mathrm{Q}}$ child-births of multiparous women; and I have ob- 음 served such an occurrence to endanger fotal life in no $\overrightarrow{\bar{O}}$ small number of those. Misplacement or unnatural shortness alone of the cord, when the fotal head is in the pelvis, and there is found plenty of room for the head to pass through, may be suspected to exist, if, during the time of the continuance of pretty strong and regular pains, the head slowly advance in a given time, and it be ascertained that the latter retreats after each pain, while previously the os uteri has become well dilated.

Nevertheless, and at the same time relying a good deal on the above signs of the existence of coiling or $ᄋ$ twisting of the fœtal cord, I have used ergot and the forceps less than formerly; preferring non-inter- 음 ference to pushing cases of this kind, when there was no urgent symptom calling for active aid; and $I N$ have never had to regret doing so. But, should the cord be supposed to be around the neck of the fœtus, o and notwithstanding it may be the chief cause of retarding the progress of the labour, when not con- N tinuing beyond a reasonable time, it is even safer to N omit than to have recourse to ergot; and there is less $\omega$ danger to foetal life, except the labour be near its termi- $\widetilde{\sigma}$ nation; then it may be found very serviceable at times.

Still there are cases, doubtless, in which it is often necessary to give ergot, and with excellent re- $\mathbb{E}$ sults; as when the labour is hindered by inefficient? uterine action, the os uteri being well dilated at the $T$ same time, the membranes broken or artificially rup- $\overline{0}$ tured, and the pelvic room being ample, with no discordance between the bony parts and the foetal head, the latter having advanced to the pelvic outlet or $\subseteq$ hollow of the sacrum.

On the contrary, it is rare to find the child alive when ergot is given too early, or some time before $?$ 